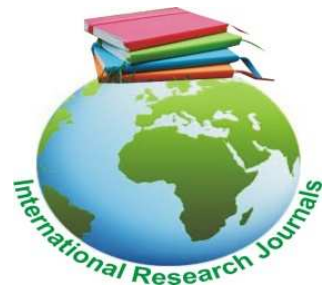

Educational Research (ISSN: 2141-5161) Vol. 9(1) pp. 001-007, January, 2018

Available online@ http://www.interesjournals.org/ER

DOI: http:/dx.doi.org/10.14303/er.2017.510

Copyright (C) 2018 International Research Journals

Full Length Research Paper

\title{
The reciprocal effects of self-concept and academic achievement scores among learners with visual impairment in primary schools, Kenya
}

\author{
Charles Michael Were \\ Maseno University, P.O. Box 333, Maseno, Kenya \\ Corresponding Author's E-mail: werecm@gmail.com
}

\begin{abstract}
Self-concept is one of the most popular ideas in psychological literature. Unfortunately, self-concept is also illusive and often poorly defined construct. Terms such as self-concept, self-esteem, self-worth, self-acceptance are often used interchangeably and inconsistently, when they may relate to different ideas about how people view themselves. The purpose of this study was therefore to determine if there were gender differences in self-concept and academic achievement among visually impaired pupils in Kenya. The population of the study was 291 visually impaired pupils. A sample of 262 respondents was drawn from the population by stratified random sampling technique based on their visual acuity. (189 partially sighted and 73 totally blind). Two instruments were used in this study: Pupils' self-concept and academic achievement tests. Data analysis was done at $p \leq 0.05$ level of significance. The $t$ test was used to test the relationship between self-concept and achievement. The data was analyzed using analysis of variance (ANOVA) structure. The study established that there was indeed a relationship in self-concept and academic achievement among visually impaired pupils in Kenya. The study therefore recommended that the lower self-concept observed among totally blind pupils should be enhanced by giving counseling and early intervention to those group of pupils with a view to helping them accept their disability.
\end{abstract}

Keywords: Self-concept, Academic Achievement, Visual Impairment, Reciprocal effects.

\section{INTRODUCTION}

Educational programming for visually impaired pupils combines basic approaches and practices. In general, such programming includes accurate diagnosis of strengths and weaknesses, special education services for deficits, accommodation of handicapped and development of selfconcept. Self-concept has been used very frequently as a variable (Byrne, 1996). Self-concept theory offers some premise in explaining important facets of children's achievement, motivation and their social behaviour in school and for evaluating the merits of various programming approaches to teaching visually impaired. It is widely accepted that an individuals' self-concept is related to school adjustment, satisfaction and achievement (Marsh, 2002). It is also widely accepted that academic achievement is more strongly related to academic self-concept and general components of self-concept. In general, research indicates that specific academic self-concepts, such as mathematics and verbal expressions are strongly positively correlated to their respective academic achievements, but are nearly uncorrelated with each other. In contrast, academic achievement in various areas is moderately to highly correlated (Marsh, 2002). However, there has been heated debate as to whether self-concept has a casual impact on academic achievement (the self-concept enhancement model) or whether academic achievement causes self-concept (the skill development model). Support for the self-concept enhancement model would provide a strong justification for self -concept enhancement intervenes in contrast; support of the skill development model implies that the best way to enhance academic self-concept is to develop 
stronger academic skills. In her initial classic review of research in this area, Byrne (1996) could only identify three studies: that is, testing the direction of causality of self-concept and achievement with paradoxical results. Potential limitations of these three studies were discussed by Marsh and Craven, (2001) who concluded that the findings varied depending on how academic achievement was inferred. It is also likely that the relationship between self-concept and academic achievement is reciprocal where by changes in academic achievement affect academic self-concepts and vice versa. Marsh and Yeung, (1997) found that prior achievement in specific subject areas affect subsequent academic related facets of self-concept and prior selfconcept affects subsequent achievement after controlling for the effects of prior achievement. These results are critical as they suggest prior self-concept has significant effects on subsequent achievement beyond the effects of prior achievement alone.

Marsh et al., (1999) updated previous reviews of his research area and emphasized that based on the existing research using strong methodology there was clear support for a reciprocal effects model in which the largest paths were from prior academic self-concept to school grades. These results imply that intervention that successfully produce changes in the appropriate area of self-concept and achievement are more likely to have long lasting effects studies that focus exclusively on academic self-concept or academic achievement alone. Marsh and Craven, (2001) emphasized that short term gains in achievement are also unlikely to be maintained unless there are corresponding gains in academic selfconcept and concluded that enhancing a child's academic self-concept is not only desirable goal but it is likely to result in improved academic achievement as well.

Relations between academic self-concept and achievement have not been examined fully from a developmental perspective. Skaalvik and Hagtret (1990), found support for a reciprocal effects model for older students (sixth and seventh grades) but found support for a skill-development model for younger students (third and fourth grades). Skaalvik, (1997) also reported support for a skill development model during elementary school years and reciprocal influences during the high school years. However, Skaalvik and Vales, (1999) did not provide support for this developmental perspective. Hence, their research has suggested stronger support for a skill development model during the early elementary school years, whereas support for a reciprocal effects model became stronger in later years.

Although scores on achievement tests are increasingly being used to make decisions that have important consequences for examinees and others.
Some of these "high-stakes" decisions are for individual students such as for, promotion, and graduation (Murphy al., 2008). Some countries and school districts also are using test scores to make performance appraisal decisions for teachers and principals and to hold schools and educational programs accountable for the success of their students (Linn, 2000). Although the policymakers who design and implement such systems often believe they lead to improved instruction, there is a growing body of evidence which indicates that high-stakes testing programs can also result in narrowing the curriculum and distorting scores (Linn, 2000). Consequently, questions are being raised about the appropriateness of using test scores alone for making high-stakes decisions (Beer et al., 2006). However, in this study, we examine score gains on academic test in an effort to assess the degree to which they provide valid information about pupil achievement in relation to self-concept and hence about improvements in achievement on a given programme and more so for the visually impaired learners.

There are also concerns that score trends may be biased by a variety of formal and informal policies and practices. For example, policies about student retention in grade may affect score trends (Fok and Fung 2004). States may vary in the extent to which their schools promote students who fail to earn acceptable grades or national examination test scores. Eliminating these socalled "social promotions" would most likely raise the average scores at each grade level in subsequent years while lowering it at each age level. This is likely to occur because although the students who are held back may continue to improve, they are likely to do so at a slower rate than comparable students who graduate with their classmates (Fok and Fung, 2004).

Another concern is inappropriate test preparation practices, including outright cheating. There have been documented cases of cheating across the nation, including National exams in Kenya. If widespread, these behaviors could substantially distort inferences from test score gains (Murphy et al., 2008). The pressure to raise scores may be felt most intensely in the lowest-scoring schools, which typically have large populations of lowincome and minority students. Students at these schools may be particularly likely to suffer from overzealous efforts to raise scores. For example, (Murphy et al., 2008) found that teachers in low-performing schools reported greater frequency of test preparation than did teachers in higher-performing schools. This could lead to a superficial appearance that the gap between minority and majority students is narrowing when no change has actually occurred.

Evidence regarding the validity of score gains on the National exams can be obtained by investigating the degree to which these gains are also present on other 
Were, 003

Table 1. The Population and Sample Frame.

\begin{tabular}{lccc}
\hline Respondents & Population & Sample & Percent \\
\hline Class 8 Pupils & 291 & 262 & 90.0 \\
\hline
\end{tabular}

measures of labour skills. Specifically, do the score trends on the National exams correspond to those on the highly job market? The National exam tests are generally recognized as the "gold standard" for such comparisons because of the technical quality of the procedures that are used to develop, administer, and score these exams, but still we cannot say that it is the best, however, it is currently the best indicator available.

There are several other reasons why score gains on the National exams are not likely to have a one-to-one match with those on job market if these tests assess different skills and knowledge. However, the specifications for the National exams are based on a consensus of a national panel of experts, including educators, about what students should know and be able to do. Hence, National examinations provide an appropriate benchmark for measuring achievement and improvement. As Linn (2000) notes, "Divergence of trends does not prove that National examination body is right and the school assessment is misleading, but it does raise important questions about the generalizability of gains reported on a teacher's own assessment, and hence about the validity of claims regarding student achievement". It is worth noting that since the introduction of 8 -4-4 system of education, the visually impaired child has been at a disadvantage and hence this study tries to find out which programme enhances self-concept and thus academic achievement.

\section{RESEARCH METHODOLOGY}

\section{Research design}

In this research, a survey and a correlation design was used. The main objective was to evaluate visually impaired pupils' self-concept and achievement in special education primary schools in Kenya. In this study, the intervening effects of sex and visual impairment relationship was of interest, since the independent variable had occurred already. Independent variables were academic self-concept, sex and visual impairment. The dependent variable was academic achievement. Sex had two levels that is male and female, visual impairment, two levels namely low vision and totally blind. Academic self-concept also had two levels; that is high achievers and low achievers. Using different categories of pupils the survey research design enabled an investigation of the interaction effects of between and within of sex, academic self-concept and achievement.

\section{Study Area}

The study was conducted in special school programmes, integrated school programme and an inclusive programme in Kenya; all are for the learners who are visually impaired. In Kenya, there are six special school programmes for primary pupils which are distributed almost equally in all the regions in Kenya except former North Eastern region. These were Kibos school for the visually impaired, St. Oda School for the visually impaired, St. Francis school for the visually impaired, St. Lucy school for the visually impaired, Likoni School for the visually impaired and Salvation army primary school for the visually impaired in Thika. The most established integrated programmes in Kenya were Kajiado Integrated programme for visually impaired, Kitui Integrated programme for visually impaired, and Kilimani Integrated programme for visually impaired in Nairobi. There was one inclusive education programme at Oriang' school, the special schools and integrated schools catered for those who were visually impaired and this include the totally blind and learners with low vision while inclusive programmes catered for children with low vision. They were all co-education.

\section{Study Population}

The population of the study consisted of 291 Class eight pupils, of which 210 were partially sighted and 81 totally blind. This number included 168 Class eight pupils in special school programme, 92 pupils of Class eight in integrated programme, 31 pupils in inclusive setting.

\section{Sample and Sampling Techniques}

A saturated sampling technique was used. The sampling 
unit consisted of all standard eight pupils in the 6 special schools, 3 integrated programmes and 1 inclusive programme. The pupils were categorized as low vision or totally blind. Low vision pupils were tested for visual acuity using the Snellen chart. The population and sampling frame is shown in table 1 above.

The following was the selection criteria for the pupils:

i) Those aged twelve years and above at the onset of the study;

ii) Consent from parent/guardian;

iii) Child willingness to participate in the study;

iv) Visual acuity of $20 / 200$ or less with a correction of glasses in the better eye.

\section{Research Instruments}

Instruments that were used to collect data were pupils' questionnaire for academic self-concept. The instruments are described below.

\section{Pupils’ Academic Achievement Test}

Achievement was measured by researcher made Academic Achievement Test which covered the following subjects: Mathematics, English, Social Studies, Kiswahili and Science. Each subject had five items. In total, there were 25 questions of multiple choice types to be answered and for each item answered correctly, 4 marks were awarded. The results were then standardized to $z$ scores using $t=10 z+50$. A score of 50 out of 100 was considered a pass while a score of below 50 was fail. The achievement test is attached as Appendix $\mathrm{C}$ for print and appendix $\mathrm{F}$ for Braille.

\section{Pupils’ Academic Self-concept Questionnaire}

This was defined as the Student's Self Description Questionnaire Individual evaluation tool (SDQI) measuring various domains of academic competence. The three facets of self-concept: general, academic and subject specifics were measured by Shavelson Evaluation Model Instrument (Marsh,2002).The instrument consisted of fifty items, which required the respondent to tick or mark the appropriate answer. Each item used a 5-point likert type scale format that ranged from strongly agree to strongly disagree, indicating the extent to which the respondent agreed or disagreed with self-descriptive statements related to their academic competence. With the realization that this instrument had not been used so far, for pupils who are blind, a pilot study was done in order to identify and change those items that could appear to be unclear or difficult for the pupils to answer. The self-concept was therefore measured by percentage scores.

According to (Marsh, 2002). This test is easy to administer, self-explanatory and can easily be understood by pupils of all grades. A score of strongly agree was marked 5 and strongly disagree marked 1 . In some items, this was reversed to avoid dishonesty in answers given. The results were then standardized to zscores using $T=(10 z+50)$. The total score was marked 100 and any score of fifty and above was considered high (L1) and below fifty considered low (L2). Psychometric properties relative to the multi component have revealed predictive validity co-efficient of 0.68 (grade 5) and 0.72 (grade 11), test re-test reliabilities of 0.64 (grade 5) and 0.72 (grade 11) over a 2 week lag. And Kuder Richardson 20 internal consistency reliabilities of 0.59 and 0.66 for grades 5 and 11 respectively (Marsh, 2002). The pupils Questionnaire on Self-concept is attached as appendix $D$ in print and appendix $G$ in Braille.

\section{Validity of the Research Instruments}

According to (Marsh, 2002). Psychometric properties relative to the multi component have revealed predictive validity co-efficient of 0.68 (grade 5) and 0.72 (grade 11) for the self-concept instruments. For face validity, all instruments were given to three experts in the area of study to establish if they captured what the study was intended to do. The instruments were then corrected by incorporating the views of these experts.

\section{Reliability of the Research Instruments}

A pilot study was undertaken in one of the schools not included in the study and this included 29 pupils of which 18 were totally blind and 11 had low vision. These children had a wide range of abilities and visual impairments, and were of the same age range and from similar background as those that were used in the study. After the pilot study it was possible to determine which researcher made items pupils answered with ease and which ones they found confusing. The items found confusing were restructured to reduce the ambiguity and therefore enhanced the suitability and reliability of the study. Split-half approach was then employed in order to establish the level of reliability which was computed using 
Were, 005

Pearson's Product Moment method. A correlation coefficient ( $r$ ) of 0.787 and 0.873 were found for selfconcept and achievement tests respectively.

\section{Data Collection Procedures}

Permission was first granted by the ministry of education to carry out research in the public schools. A visit was made to the schools by the researcher and rapport was established between the researcher and the class teachers. During the administration of the research instruments, the researcher was assisted by the head teachers and the class teachers. All information given was treated with confidentiality. Explicit instructions were given verbally to ensure that the respondents understood the questions. There were sample questions in the form of examples which were read to all respondents and answered verbally before beginning the test. During the administration of the test, totally blind pupils used Braille writing, while low vision respondents used large print. For those who could not read, the class teacher assisted them in reading.

\section{Data Analysis Procedures}

All procedures based on the analyses of variance structure were conducted. In order to facilitate interpretation, negative items were reversed such that high scores represented high positive perception. Academic self-concept was described best by three factors namely, general self-concept, academic and subject specific. A score of fifty out of one hundred for Self-concept was considered a pass, while a score below fifty out of one hundred failed. The mean and standard deviation was used to indicate how widely spread values are from the mean. Data analyses at p 0.05 level of significance were tested. $F$ test was used to test the statistical significance of the postulated null hypotheses. Simple frequencies and percentages were calculated to enable an investigation of comparison on the responses of various groups for each question or item. Analyses of Variance (ANOVA) were used to measure the interaction effect of the dependent and independent variables.

\section{RESULTS AND DISCUSSION}

Determining the relationship between self-concept and achievement for learners who are visually impaired. A look at Table 2 also shows that pupils who scored high in self - concept also performed better in achievement scores. The study attempted to determine if there was any difference in relationship between self-concept and achievement among pupils who are visually impaired by testing the following hypothesis:

H01 There is no significant relationship between selfconcept and achievement for learners who are visually impaired.

Pearson's Product-Moment Correlation coefficient, or Pearson's "r" was used to calculate the value for "r" and using the table to determine the critical value $(\mathrm{cv})$. In this case the number of pairs $\mathrm{n}$ was 189 for partially sighted and 73 for totally blind. Taking $(n-2)$ as the df being 187 for partially sighted and 71 for the totally blind. Where $n$ referred to the number of pairs of scores that is selfconcept and achievement. The calculated value was found to be 0.771 for partially sighted and 0.638 for those who were totally blind. In the table of critical value for Pearson's "r", two critical values of $p \leq 0.05$ and $p \leq 0.01$ was 0.195 and 0.164 respectively. The calculated value was found to be greater than the two critical values at $p \leq$ 0.05.and $p \leq 0.01$ on the table of values, therefore the null hypothesis was rejected and the alternative hypothesis taken, that is there was a significant relationship between self-concept and achievement for pupils who are visually impaired. These findings are also summarized on Table 3.

Results of the data analysis showed that there is indeed a relationship between self- concept and achievement for learners who are visually impaired. Those who had higher scores in self-concept were also high achievers in academic achievement scores. The finding is also supported by Somerset (1971) and Mwaniki (1973), which indicated a strong correlation between self-concept and mathematics achievement. It is also shown that those who scored low in self-concept also scored low in academic achievement, the one that has been the most perplexing and illusory has been the question of whether academic self-concept causes academic achievement, or whether instead, academic achievement causes academic self-concept.

In reviewing such claims of casual predominance (Byrne, 1996) found that for every study that argued for the impact of academic self-concept on academic achievement, there was a comparable one that claimed the reverse to be true. Of the 23 studies, 11 argued for casual self-concept flow, and one was unable to determine direction. Following a review of published studies and 18 doctoral dissertations concerned with the 
Table 2. Relationship between Self-Concept and achievement

\begin{tabular}{lcclc}
\hline Source & Sample $\mathbf{n}$ & df. & Calc. Vale & Critical Value \\
\hline Partially sighted & 189 & 187 & 0.771 & $0.195 / 0.164$ \\
Totally Blind & 73 & 71 & 0.638 & $0.195 / 0.164$ \\
Total & 263 & & & \\
\hline
\end{tabular}

Table 3. Comparison of self concept scores and achievement among the low vision and totally blind learners.

\begin{tabular}{lccccc}
\hline SELF- & \multicolumn{2}{c}{ VISION } & ACHIEVEMENT & \multicolumn{2}{c}{ VISION } \\
\hline CONCEPT & $\begin{array}{c}\text { Low } \\
\text { vision }\end{array}$ & $\begin{array}{c}\text { Totally } \\
\text { blind }\end{array}$ & SCORE & Low vision & Totally blind \\
& 0 & 2 & $10-19$ & 0 & 2 \\
$10-19$ & 8 & 2 & $20-29$ & 8 & 2 \\
$20-29$ & 12 & 4 & $30-39$ & 12 & 4 \\
$30-39$ & 21 & 10 & $40-49$ & 21 & 10 \\
$40-49$ & 34 & 8 & $50-59$ & 32 & 11 \\
$50-59$ & 32 & 19 & $60-69$ & 34 & 19 \\
$60-69$ & 53 & 11 & $70-79$ & 21 & 15 \\
$70-79$ & 21 & 15 & $80-89$ & 53 & 2 \\
$80-89$ & 8 & 2 & $90-99$ & 8 & $\mathbf{7 3}$ \\
$90-99$ & $\mathbf{1 8 9}$ & $\mathbf{7 3}$ & & $\mathbf{1 8 9}$ & \\
TOTAL & & & & & \\
\hline
\end{tabular}

impact of intervention programmes on the self-concept and academic achievement of school children. (Byrne, 1996) reported no evidence of casual connection between the two constructs; these same conclusions were drawn earlier by Skaalvik and Hagtret (1990).

In sharp contrast, however, the West et al. (1980) review concluded, "Findings are now sufficient to indicate that school achievement is casually predominant over self-concept of academic ability. One major limitation of the preceding studies and therefore failed to meet the necessary criterion of temporal precedence in the determination of cause (Cook and Campbell, 1979). This criterion demands that to assess, for example, whether self-concept influences academic achievement, selfconcept must precede academic achievement in time.

\section{CONCLUSIONS AND RECOMMENDATIONS}

\section{CONCLUSIONS}

$\mathrm{HO}_{2}$ There is no difference in achievement among visually impaired pupils

Since low vision pupils scored higher in achievement tests than their totally blind counterparts, this suggests that level of visual impairment negatively influences academic achievement. That is, the greater the impairment, the lower the achievement.

$\mathrm{HO}_{3}$ There is no significant relationship between self concept and achievement for visually impaired pupils

Results of the data analysis showed that there is a positive correlation between self- concept and achievement for visually impaired pupils. The study therefore concluded that self-concept positively influences the pupils' academic achievement.

\section{RECOMMENDATIONS}

i. The study therefore recommends that the lower selfconcept observed among totally blind pupils should be enhanced by giving counselling and early intervention to those group of pupils with a view to helping them accept their disability. 
Were, 007

\section{REFERENCES}

Byrne BM (1996). "Academic Self-Concept: Its Structure, Measurement, and Relation to academic achievement". In

B.A. Bracken (Ed.) Handbook of self - concept ( $\mathrm{pp}$ 287-316). New York: Wiley.

Fox and Fung (2009). self concept esteem, personality traits and psychopathological visual; impairment. The Spanish Journal of psychology. Linn, R.L. (2000) Assessments and accountability Educational research, 29(2) 4-16

Marsh HW (2002). Physical self-concept: Theory, measurement and research. Keynote Address to Intl. Congress of sports psychology, Skiathes, Greece. The J. the Hellenic Psychology Society, 9, $459-493$.

Marsh HW, Craven RG (2001). The Pivotal Role of Frames of Reference in Academic Self-Concept Formation: The Big Fish Little Pond Effect. In F. Pajeres and T. Urden (eds) Adolescence and education, vol. 2: 83-23.

Marsh HW, Byrne BM, Yeung AS (1999). Causal ordering of academic self-concept and achievement: Reanalysis of a pioneering study and revised recommendations. Educational Psychologist, 34, 155-167.

Murphy JL, Hatton D, Erickson KA (2008). Exploring the early literacy practices of teachers of infants. Toddlers, and preschoolers with visual impairments. J. visual impairment and blindness. 102 (3), 144-146.

Skaalvik EM, Hagtvet KA (1990). Academic Achievement and Self-Concept: An Analysis of Cansel predominance in a Developmental; Perspective. J. Personality and Social Psychology, vol. 58: 292-307.

Skaalvik EM (1997). Issues in Research on Self-Concept in Mn. Maehr and P.R. Pintich (Eds), Advances in Motivation and Achievement, vol. 10: 51-99.

Skaalvik EM, Vales H (1999). Achievement and Self-Concept in Mathematics and Verbal Arts: A Study of Relations. Montreal, Canada: Seminar Paper.

Marsh HW, Yeung AS (1997). Counsel Effects of Academic Self-Concept on Academic Achievement: Structural Equation Models of Longitudinal Data. J. Edu. Psychol. 89: 41-54. 